\title{
PRODUTIVIDADE DE Brachiaria brizantha (Hochst. ex A. Rich.) Stapf cv. Marandu SOB DIFERENTES ARRANJOS ESTRUTURAIS DE SISTEMA AGROSSILVIPASTORIL COM EUCALIPTO
}

\author{
Productivity of Brachiaria brizantha (Hochst. ex A. Rich.) Stapf cv. Marandu under different \\ spacings on agrosylvopastoral system with eucalypt
}

\author{
Tadário Kamel de Oliveira1, Renato Luiz Grisi Macedo²,Ívina Paula Almeida dos Santos 3 , \\ Emílio Manabu Higashikawa ${ }^{4}$, Nelson Venturin ${ }^{5}$
}

\begin{abstract}
RESUMO
O sucesso de sistemas de produção sustentáveis tem como aspecto fundamental a escolha das espécies. O conhecimento da tolerância da Brachiaria brizantha (Hochst. ex A. Rich.) Stapf ao sombreamento e seu desempenho em consórcio com eucalipto implica na recomendação desta forrageira para implantação de sistemas agrossilvipastoris. O objetivo deste trabalho foi avaliar quantitativa e qualitativamente a produtividade de Brachiaria brizantha (Hochst. ex A. Rich.) Stapf cv. Marandu sob diferentes arranjos estruturais de sistema agrossilvipastoril com eucalipto. Realizou-se o plantio de mudas clonais de um híbrido natural de Eucalyptus camaldulensis Dehnh com Eucalyptus urophylla S.T. Blake, em dezembro de 1999, em área de cerrado, no noroeste de Minas Gerais (Paracatu-MG, Brasil). Fez-se o plantio em consórcio com arroz no primeiro ano, soja no segundo e em seguida braquiária, semeada em dezembro de 2001. O experimento foi implantado no delineamento blocos casualizados, em esquema de parcelas subdivididas, com quatro repetições. Nas parcelas foram alocados os arranjos do eucalipto, em linhas duplas: $(3 \times 3)+10 \mathrm{~m},(3 \times 4)+7 \mathrm{~m},(3 \times 4)+10 \mathrm{~m},(3 \times 4)+7+10 \mathrm{~m},(3 \times$ $3)+15 \mathrm{~m}$; e linhas simples: 10x3m, e 10x4m. As subparcelas corresponderam às avaliações na linha e na entrelinha de plantio. Foram avaliados o rendimento e aspectos de qualidade da forragem, bem como a densidade de fluxo de fótons fotossinteticamente ativos no subbosque, em cada arranjo. Verificou-se que a forragem disponível (matéria natural e matéria seca) foi sempre maior na entrelinha do que na linha de plantio, independente do arranjo. Os variados arranjos do sistema agrossilvipastoril praticamente não provocaram variação no teor de fibras, $\mathrm{N}$ e $\mathrm{P}$ na forragem. As concentrações de $\mathrm{Ca}, \mathrm{K}$ e $\mathrm{Mn}$ foram maiores na braquiária sob as linhas de plantio do eucalipto e as concentrações de $\mathrm{Mg}$ e $\mathrm{Zn}$ maiores na entrelinha de plantio.
\end{abstract}

Termos para indexação: Forragem, qualidade, consórcio, espaçamento, sistema silvipastoril.

\begin{abstract}
The choice of species is the main factor on the establishment of the sustainable system production. The tolerance of Brachiaria brizantha (Hochst. ex A. Rich.) Stapf for shade let this species to be recommended to implement the sylvopastoral and agrosylvopastoral systems. The objective of this work was to evaluate the productive performance of Brachiaria brizantha (Hochst. ex A. Rich.) Stapf cv. Marandu under different spacings on agrosylvopastoral systems with eucalypt. In December 1999 was planted (in Paracatu-MG, Brasil) seedling seed orchard of natural hybrid of Eucalyptus camaldulensis Dehnh x Eucalyptus urophylla S.T. Blake, intercropped with rice in the first year and soybean in the second one. After annual cropping cultivation, was planted the forage, in December 2001. The experimental design used was the randomized blocks, with four repetitions, in split plot, and seven spacings of eucalypt stand $[(3 \times 3)+10 \mathrm{~m},(3 \times 4)+7 \mathrm{~m},(3 \times 4)+10 \mathrm{~m},(3 \times 4)+7+10 \mathrm{~m},(3 \times 3)+15 \mathrm{~m}, 10 \times 3 \mathrm{~m}$ and $10 \times 4 \mathrm{~m}]$. Each split plots, the forage was planted in row and between rows of eucalypt. The photosynthetic photon flux density understory of the stand, the natural and dry matter production and forage quality of Brachiaria brizanhta pasture was evaluated. The results showed that the Brachiaria brizantha forage was higher between rows (shaded) than in rows, independent of the spacing, which not promoted changes in the grass content fiber. There were not significant different among spacings or rows and between rows to $\mathrm{N}$ and $\mathrm{P}$ nutrients content in forage, but the $\mathrm{Ca}, \mathrm{K}$ and $\mathrm{Mn}$ content were highest under rows.
\end{abstract}

Index terms: Forage quality, consortium, spacing, sylvopastoral system.

(Recebido em 23 de março de 2005 e aprovado em 6 de dezembro de 2005)

\section{INTRODUÇÃO}

As espécies Brachiaria brizantha (Hochst. ex A. Rich.) Stapf e Brachiaria decumbens Stapf. são amplamente utilizadas para a formação de pastagens no cerrado, geralmente em extensas áreas destinadas à atividade pecuária. Grandes áreas no cerrado também são dispensadas para a cultura do eucalipto, espécie florestal

\footnotetext{
'Engenheiro Agrônomo, D.Sc., Pesquisador da Embrapa Acre - BR 364, km 14 - 69908-970 - Rio Branco - AC - tadario@cpafac.embrapa.br 2Engenheiro Agrônomo/Engenheiro Florestal, D.Sc., Professor do Departamento de Ciências Florestais/DCF - Universidade Federal de Lavras/ UFLA - 37200-000 - Lavras, MG - rlgrisi@ufla.br

${ }^{3}$ Engenheiro Agrônomo, D.Sc., Zootecnia - Forragicultura e pastagem - Bolsista Prodoc/CAPES - Universidade Estadual do Sudoeste da Bahia/ UESB - Praça primavera, n. 40 - Campus de Itapetinga - 45700-000 - Itapetinga, BA - ivinapaulaa@yahoo.com.br

${ }^{4}$ Discente do curso de Engenharia Florestal - Universidade Federal de Lavras/UFLA - 37200-000 - Lavras, MG -UFLA - emilio.higashikawa@gmail.com ${ }^{5}$ Engenheiro Florestal, D.Sc., Professor do Departamento de Ciências Florestais/DCF - Universidade Federal de Lavras/UFLA - 37200-000 Lavras, MG - venturim@ufla.br
} 
que possivelmente deverá suprir a demanda de madeira cada vez maior (SBS, 2005; SILVA, 2002). Todavia, tanto a atividade pecuária quanto florestal, em grandes áreas, geram concentração de terra e necessitam de grande capital para investimento. Formas de uso da terra que agregam retorno econômico a serviços ambientais estão sendo procuradas cada vez mais. A implantação de sistemas silvipastoris e agrossilvipastoris atendem estes requisitos ao integrar a atividade florestal e pecuária.

Estudos foram desenvolvidos na Zona da Mata de Minas Gerais, avaliando o consórcio de Eucalyptus grandis Hill ex Maiden com gramíneas. A escolha das espécies foi em decorrência das pastagens na região serem formadas na sua maioria por Brachiaria decumbens e os povoamentos de eucalipto, dependendo da espécie e a partir de certa idade, possibilitarem a penetração de luz para o sub-bosque, quando convenientemente espaçados (SILVA, 1999).

O conhecimento das condições para o cultivo nas entrelinhas de povoamentos de eucalipto torna-se um importante fator. Padrões de distribuição espacial de comunidades campestres sob plantio de eucalipto foram avaliados por Pillar et al. (2002). Os autores concluíram que comunidades localizadas em sítios menos sombreados tendem a ter maior cobertura do solo com espécies $\mathrm{C}_{4}$, ao passo que sob sombreamento intermediário e mais intenso, a comunidade de plantas do sub-bosque apresenta maioria das espécies como $\mathrm{C}_{3}$. Isto indica que espaçamentos e arranjos mais amplos nos plantios de eucalipto devem ser avaliados visando ao favorecimento das gramíneas forrageiras tropicais $\left(\mathrm{C}_{4}\right)$, na implantação de sistemas silvipastoris e agrossilvipastoris.

Castro et al. (1998) citam a necessidade de maiores informações sobre o comportamento das principais forrageiras tropicais como as do gênero Brachiaria que, sob luminosidade reduzida, têm sua composição química e digestibilidade afetadas.

Diversos autores classificam como média a tolerância da Brachiaria brizantha ao sombreamento e recomendam esta forrageira para implantação de sistemas silvipastoris e agrossilvipastoris (COSTA \& TOWNSEND, 2002; RIBASKI \& RAKOCEVIC, 2002).

Um requisito fundamental para o sucesso de sistemas agrossilvipastoris sustentáveis é a escolha das espécies para o sistema. As forrageiras devem ser produtivas, além de tolerantes ao sombreamento, e adaptadas às condições edafoclimáticas do local de implantação. Isto é mais relevante em se tratando de área de cerrado, com características particulares de solos ácidos, de baixa fertilidade e estação seca bem definida e prolongada (ANDRADE et al., 2003).

A otimização do uso da área, preparo do solo, insumos e a diversificação da produção, tornam sistemas agrossilvipastoris mais complexos que os sistemas de produção convencionais. Portanto, necessita-se de maior número de pesquisas sobre formas de implantação, componentes agrícolas e florestais, manejo e exploração. $\mathrm{O}$ objetivo deste trabalho foi avaliar o desempenho produtivo de Brachiaria brizantha (Hochst. ex A. Rich.) Stapf cv. Marandu sob diferentes arranjos estruturais de sistema agrossilvipastoril com eucalipto no cerrado de Minas Gerais.

\section{MATERIAL E MÉTODOS}

O estudo foi desenvolvido na Fazenda Riacho, propriedade da Companhia Mineira de Metais - CMM Agroflorestal, em área de cerrado, no noroeste de Minas Gerais (Paracatu-MG), situada a $17^{\circ} 36^{\prime}$ de latitude Sul e $46^{\circ} 42^{\prime}$ de longitude Oeste, com altitude de $550 \mathrm{~m}$.

O clima da região é tropical úmido de savana, tipo Aw, com inverno seco e verão chuvoso, conforme a classificação de Köppen. A temperatura média anual é de $22,6^{\circ} \mathrm{C}$. A precipitação média anual é de $1450 \mathrm{~mm}$, concentrada principalmente nos meses de novembro a fevereiro. O solo predominante na área é o Latossolo Vermelho-Amarelo Distrófico típico.

O experimento foi instalado em dezembro de 1999 , em um sistema agrossilvipastoril seqüencial, constituído pelo plantio de mudas clonais de um híbrido natural de Eucalyptus camaldulensis Dehnh com Eucalyptus urophylla S.T. Blake, selecionado para produção de madeira para serraria. Foi estabelecido o consórcio com arroz no primeiro ano, seguido de soja no segundo. Ao longo dos anos de plantio, foram realizados todos os tratos culturais e silviculturais necessários para cada cultura, respeitando-se as suas respectivas recomendações técnicas (MACEDO \& OLIVEIRA, 1996). Após as culturas agrícolas (arroz e soja) foi realizado em dezembro de 2001 o plantio de Brachiaria brizantha (Hochst. ex A. Rich.) Stapf cv. Marandu, por meio de semeadura a lanço (10 kg/ha).

O delineamento utilizado foi blocos casualizados em esquema de parcelas subdivididas, com quatro repetições. Nas parcelas, estudou-se o efeito de sete arranjos estruturais do sistema agrossilvipastoril com eucalipto, em linhas duplas: $(3 \times 3)+10 \mathrm{~m},(3 \mathrm{x} 4)+7 \mathrm{~m},(3 \mathrm{x}$ 4)+10 m, (3 x 4)+7+10 m, (3 x 3)+15 m; e em linhas simples: $10 \times 3 \mathrm{~m}$, e $10 \times 4 \mathrm{~m}$. As subparcelas corresponderam às avaliações realizadas na linha e na entrelinha de plantio. As parcelas experimentais estão descritas na Tabela 1. 
TABELA 1 - Descrição do número de árvores e linhas da parcela útil, altura de plantas e diâmetro à altura do peito (DAP), para os diferentes arranjos estruturais do sistema agrossilvipastoril com eucalipto, aos 27 meses, em Paracatu, MG.

\begin{tabular}{llcc}
\hline $\begin{array}{c}\text { Arranjos } \\
\text { Estruturais* }\end{array}$ & Parcela útil & Altura de plantas $(\mathbf{m})$ & $\begin{array}{c}\text { DAP } \\
(\mathbf{c m})\end{array}$ \\
\hline$(3 \times 3)+10 \mathrm{~m}$ & 4 linhas de 7 árvores & 12,11 & 11,01 \\
$(3 \times 4)+7 \mathrm{~m}$ & 4 linhas de 5 árvores & 12,17 & 11,08 \\
$(3 \times 4)+10 \mathrm{~m}$ & 4 linhas de 4 árvores & 10,23 & 11,78 \\
$(3 \times 4)+7+10 \mathrm{~m}$ & 6 linhas de 3 árvores & 12,53 & 12,81 \\
$(3 \times 3)+15 \mathrm{~m}$ & 4 linhas de 5 árvores & 11,97 & 12,68 \\
$10 \times 3 \mathrm{~m}$ & 3 linhas de 5 árvores & 12,12 & 13,16 \\
$10 \times 4 \mathrm{~m}$ & 2 linhas de 5 árvores & 12,06 & 13,62 \\
\hline
\end{tabular}

*A bordadura foi representada por uma linha de cada lado da parcela útil e duas plantas nas cabeceiras, em cada linha da parcela.

Em abril de 2002, foi caracterizada a radiação fotossinteticamente ativa no sub-bosque de cada arranjo, sob as linhas e nas entrelinhas de plantio do eucalipto, exceto para o $(3 \times 4)+7+10$. Fez-se a mensuração da densidade de fluxo de fótons fotossinteticamente ativos (DFF), utilizando-se um medidor de radiação (LI-250 Light Meter - LI-COR), no qual foi acoplado um quantômetro (LI-190SA Quantum Sensor-LI-COR) (LI-COR, 1991). As medidas foram tomadas entre as 11:00 h e 14:00 h, em dias com céu predominantemente claro (pouca ou nenhuma nebulosidade). $\mathrm{O}$ sensor foi posicionado a $0,50 \mathrm{~m}$ de altura do solo e cada medida correspondeu ao valor médio da radiação incidente no sensor, medida durante 15 segundos.

Para a braquiária, fez-se avaliação das seguintes variáveis: 1) Produtividade de matéria natural (MN). Para avaliação da entrelinha, foram demarcados $2 \mathrm{~m}^{2}$ com um quadro de madeira, na entrelinha central da parcela útil. Para avaliação da linha, foram demarcados $2 \mathrm{~m}^{2}$ com um quadro de madeira entre duas plantas da linha central da parcela útil. Nas áreas demarcadas, todas as plantas foram cortadas $10 \mathrm{~cm}$ acima do nível do solo e pesadas, transformando-se os valores em t/ha; 2) Produtividade de matéria seca (MS). Foram retiradas amostras de $300 \mathrm{~g}$ de $\mathrm{MN}$ da linha e entrelinha de cada arranjo estrutural, em quatro repetições. As amostras foram colocadas em sacos de papel e em estufa com ventilação forçada, a $65^{\circ} \mathrm{C}$, até atingirem estabilização do peso. A porcentagem de MS em cada amostra correspondia ao teor de MS. A produtividade de MS foi calculada por meio do produto do teor de MS com a produção de MN em cada parcela, transformado-se os valores em t/ha; 3 ) Teores de fibra em detergente neutro (FDN) e fibra em detergente ácido (FDA) na MS; 4) Teores de macro e micronutrientes na MS da parte aérea; e 5) Teor de proteína bruta na forragem, calculado mediante à multiplicação do teor de $\mathrm{N}(\%)$ pelo fator de correção $(6,25)$ em cada arranjo.

Após análise de homogeneidade de variâncias, verificou-se a necessidade de transformação dos dados de MN e MS, que foram transformados em $\log x$. Os dados obtidos foram submetidos à análise de variância, fazendose os desdobramentos quando necessários. Para os efeitos significativos de tratamentos da parcela (arranjos estruturais), aplicou-se às médias o teste de Tukey, a 5\% de probabilidade. Para os efeitos significativos verificados nas subparcelas, referentes a linha e entrelinha de plantio, aplicou-se o teste $\mathrm{t}(\mathrm{P}<0,05)$.

\section{RESULTADOS E DISCUSSÃO}

Com relação à disponibilidade de matéria natural e matéria seca, os efeitos dos arranjos e linha e entrelinha foram significativos, mas independentes, ou seja, a diferença na produção de forragem na linha e entrelinha de plantio foi detectada independentemente do arranjo e viceversa. Houve diferença significativa da interação linha e entrelinha com os arranjos estruturais para FDN e FDA.

Matéria natural e seca apresentaram os mesmos resultados estatísticos, sendo que as maiores produtividades foram obtidas no arranjo $(3 \times 3)+10 \mathrm{~m}$, o qual não diferiu estatisticamente dos demais, exceto $\mathrm{o} 10 \mathrm{x}$ $3 \mathrm{~m}$, que apresentou produção de biomassa significativamente inferior (Tabela 2), possivelmente em razão de problemas na formação da pastagem sob este tratamento. Em geral, os valores obtidos foram baixos, média de $1,8 \mathrm{t} /$ ha de matéria seca, comparado a 3,1 t/ha no período

Ciênc. agrotec., Lavras, v. 31, n. 3, p. 748-757, maio/jun., 2007 
chuvoso, encontrados por Costa et al. (1998), trabalhando na região amazônica. Deve-se considerar que no período seco estes autores verificaram 1,6 t/ha de matéria seca para o Brachiaria brizantha, o que coincide com a avaliação do presente estudo, em abril de 2002, quando a precipitação foi bastante reduzida, mesmo em se tratando do final do período das chuvas. A Brachiaria brizantha produziu no período seco, sob povoamento de eucalipto no espaçamento $3,33 \times 3 \mathrm{~m}, 2,0$ t/ha de matéria seca, em trabalhos de Costa \& Townsend (2002).

Vale mencionar a cobertura do solo acima de $95 \%$ e a produtividade ao redor de 4,5 t/ha de MS de Brachiaria brizantha cv. Marandu, obtida por Andrade et al. (2003), em cultivo solteiro e consorciado com Stylosanthes guianensis var. vulgaris MB Ferr. et NMS Costa cv. Mineirão, na mesma região do presente estudo.

Considerando a baixa quantidade de chuvas no mês da avaliação da forrageira (abril/2002), deve-se destacar que a biomassa produzida pela Brachiaria brizantha $\mathrm{cv}$. Marandu na época seca representa apenas 10-20\% da produção anual, segundo Soares Filho (2001).

Quanto à produção de forragem na linha e na entrelinha, a MN (Figura 1) e MS (Figura 2) foram sempre maiores na entrelinha de plantio, possivelmente em razão de ausência ou menor competição proporcionada pelo eucalipto.

TABELA 2 - Matéria natural e matéria seca de Brachiaria brizantha em diferentes arranjos estruturais do sistema agrossilvipastoril com eucalipto, em Paracatu - MG.

\begin{tabular}{lcc}
\hline \multicolumn{1}{c}{ Arranjos } & Matéria natural (t/ha) & Matéria seca (t/ha) \\
\hline$(3 \times 3)+10 \mathrm{~m}$ & $7,07 \mathrm{a}$ & $2,79 \mathrm{a}$ \\
$(3 \times 4)+7 \mathrm{~m}$ & $3,44 \mathrm{ab}$ & $1,42 \mathrm{ab}$ \\
$(3 \times 4)+10 \mathrm{~m}$ & $5,47 \mathrm{ab}$ & $2,11 \mathrm{ab}$ \\
$(3 \times 4)+7+10 \mathrm{~m}$ & $5,18 \mathrm{ab}$ & $1,91 \mathrm{ab}$ \\
$(3 \times 3)+15 \mathrm{~m}$ & $4,17 \mathrm{ab}$ & $1,80 \mathrm{ab}$ \\
$10 \times 3 \mathrm{~m}$ & $2,45 \mathrm{~b}$ & $1,06 \mathrm{~b}$ \\
$10 \times 4$ m & $3,84 \mathrm{ab}$ & $1,63 \mathrm{ab}$ \\
\hline Média geral & 4,52 & 1,82 \\
\hline
\end{tabular}

Médias seguidas pela mesma letra nas colunas não diferem entre si pelo teste Tukey $(\mathrm{P}<0,05)$.

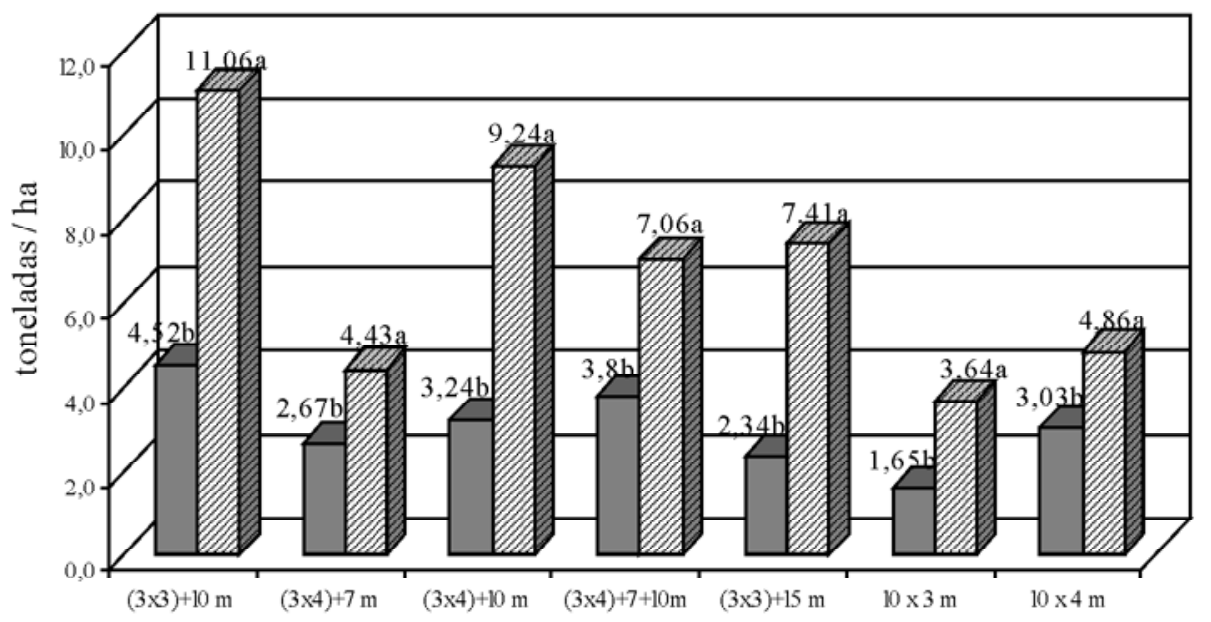

FIGURA 1 - Matéria natural de Brachiaria brizantha na linha e na entrelinha de plantio de diferentes arranjos estruturais de sistemas agrossilvipastoris com eucalipto (Para cada arranjo, médias com mesma letra não diferem entre si pelo teste t. $\mathrm{P}<0,05$ ). 


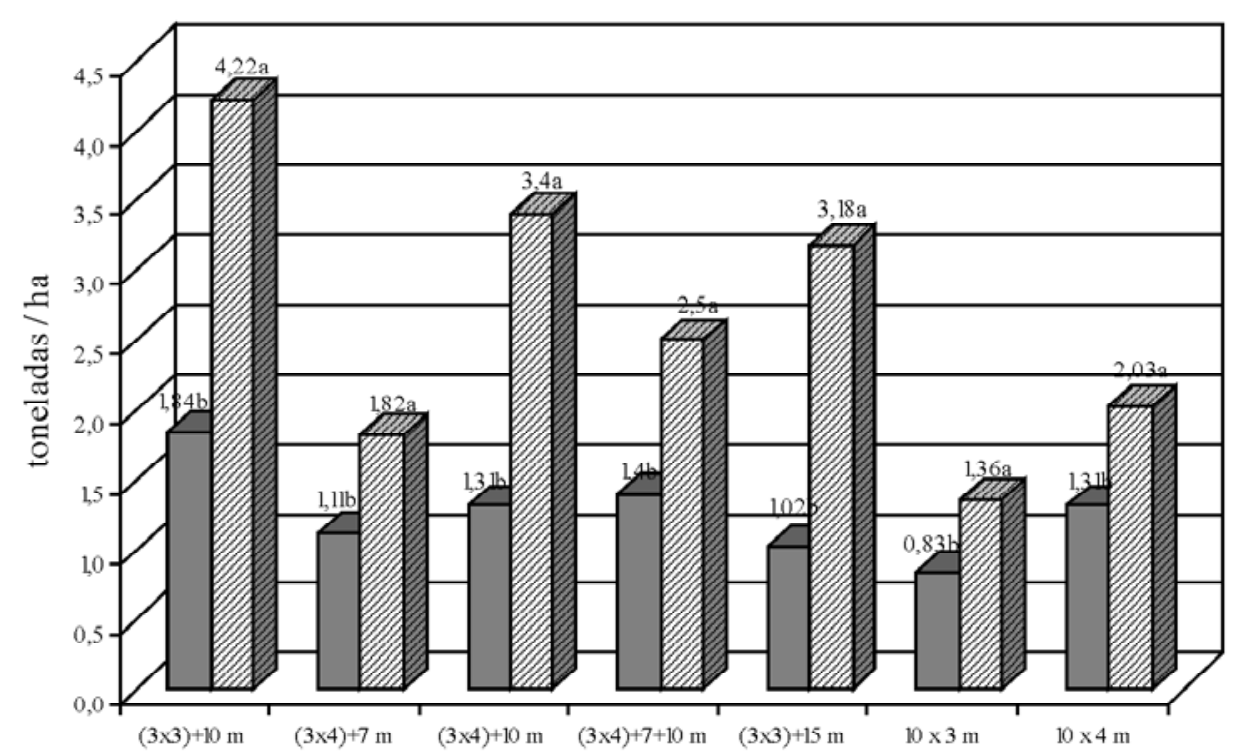

FIGURA 2 - Matéria seca de Brachiaria brizantha na linha e na entrelinha de plantio de diferentes arranjos estruturais de sistemas agrossilvipastoris com eucalipto (Para cada arranjo, médias com mesma letra não diferem entre si pelo teste t. $\mathrm{P}<0,05$ ).

Vale ressaltar que, embora a braquiária sombreada (entrelinha) tenha apresentado maior produção de matéria seca (Figura 2), a radiação fotossinteticamente ativa, expressa pela densidade de fluxo de fótons (Figura 3), em geral, foi maior na linha de plantio dos diferentes arranjos, à exceção do $(3 \times 3)+15$ m. A maior produção de forragem na entrelinha de plantio condiz com as constatações de Ribaski \& Rakocevic (2002). Os autores atribuíram à competição, principalmente por água, o menor desempenho da braquiária sob a copa das árvores.

A maior radiação solar incidente na linha pode ter ocasionado maior evapotranspiração e, conseqüentemente, menor disponibilidade hídrica para o eucalipto e a braquiária, dificultando o acúmulo de forragem pela gramínea na linha de plantio das árvores. À sombra, o efeito da alta luminosidade sob a elevação da temperatura pode ser atenuado, o que justifica a produção de matéria seca na entrelinha superior àquela sob a copa do eucalipto no presente estudo (Figura 2).

Estes resultados confirmam as discussões apresentadas por Silva et al. (1999), avaliando Brachiaria brizantha em sistema silvipastoril com Grevillea robusta A. Cunn. Embora os autores tenham observado maior produção de MS da gramínea sob a copa das árvores, a radiação fotossinteticamente ativa foi menor. A maior produção de forragem na linha se justificou pela interação, mais positiva que na entrelinha, da radiação solar com outros fatores de produção (umidade, temperatura e fertilidade do solo). Foi citado que em um dia de verão a temperatura ao centro da entrelinha atingiu $8^{\circ} \mathrm{C}$ a mais que sob a copa das árvores, o que pode ter promovido efeitos negativos no processo fotossintético, por meio do fechamento dos estômatos e e limitação à entrada de $\mathrm{CO}_{2}$ na folha.

Os resultados para FDN e FDA (Tabela 3) mostraram que não houve diferença significativa entre os arranjos quanto à FDN na linha, mas que na entrelinha a maior porcentagem de fibra foi encontrada na forragem sob o arranjo (3 x 3)+10 m.

Para FDA, não se encontrou diferença significativa entre os arranjos. Porém, avaliando os arranjos separadamente, na entrelinha dos arranjos ( $3 \times 4)+7 \mathrm{me} \mathrm{(3}$ x 3)+15 m observou-se menores valores de FDA na forragem de braquiária em relação à linha.

Deve-se ressaltar que os valores médios de FDN (acima de 72\%) e FDA (ao redor de 40\%) estão de acordo com os encontrados por outros autores. Gomes (2003) constatou 78,56\% de FDN e 49,56\% de FDA na forragem de Brachiaria brizantha avaliada no mês de abril, em condição climática semelhante à do presente estudo.

Outros autores, como Aroeira et al. (2004), encontraram valores de FDN de 70,2 a 79,7\% e os de FDA de 35,3 a 46,5\%, o que implicou em baixa digestibilidade da forragem de Brachiaria decumbens. 


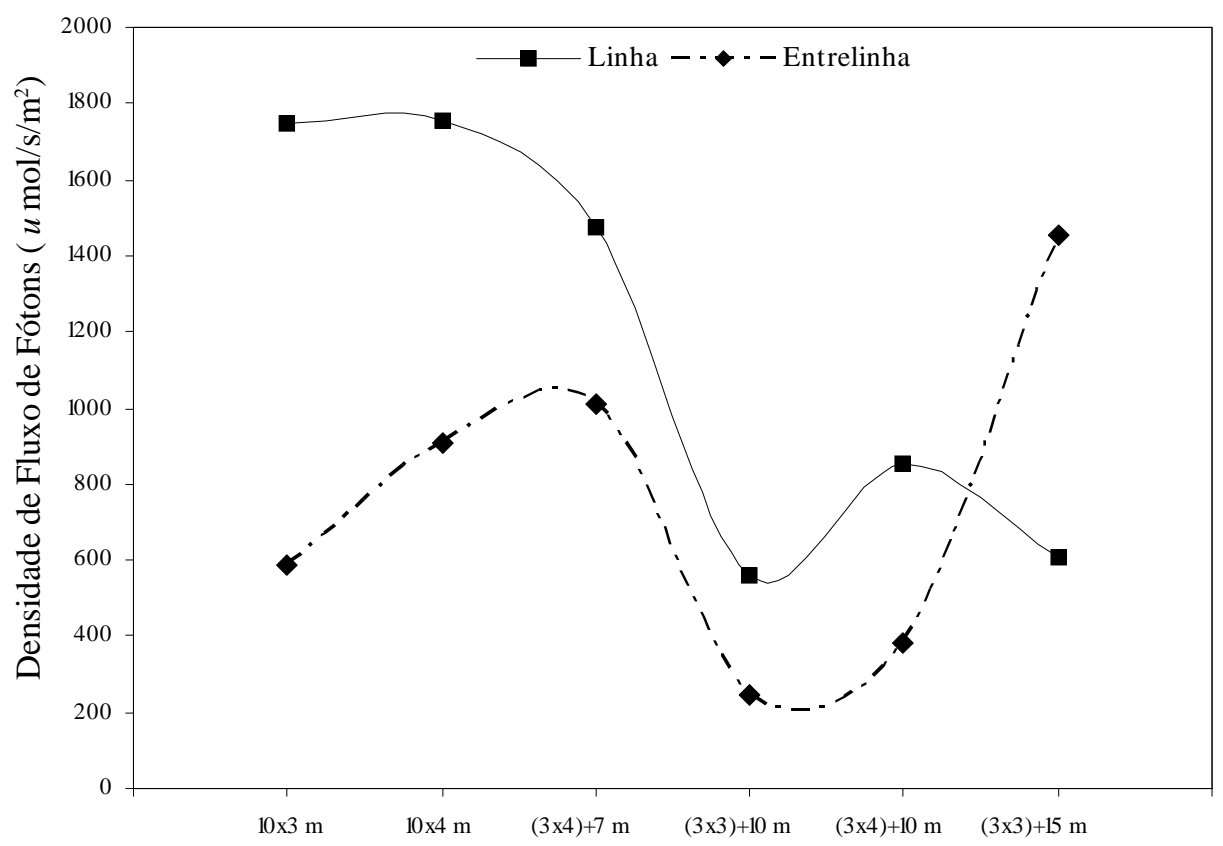

FIGURA 3 - Densidade de fluxo de fótons $\left(\mu \mathrm{mol} / \mathrm{s} / \mathrm{m}^{2}\right)$ na linha e na entrelinha de plantio de diferentes arranjos estruturais de sistemas agrossilvipastoris com eucalipto, aos 27 meses após o plantio, em Paracatu, MG.

TABELA 3 - Fibra em detergente neutro (FDN) e fibra em detergente ácido (FDA) de Brachiaria brizantha, na linha e na entrelinha de plantio de diferentes arranjos estruturais do sistema agrossilvipastoril com eucalipto, em Paracatu, MG.

\begin{tabular}{lcccccc}
\hline \multirow{2}{*}{ Arranjos } & \multicolumn{3}{c}{ FDN $(\boldsymbol{\%})$} & \multicolumn{3}{c}{ FDA (\%) } \\
\cline { 2 - 7 } & Linha & Entrelinha & Média & Linha & Entrelinha & Média \\
\hline$(3 \times 3)+10 \mathrm{~m}$ & $74,92 \mathrm{aA}$ & $76,98 \mathrm{a} \mathrm{A}$ & $75,95 \mathrm{a}$ & $41,19 \mathrm{aA}$ & $41,77 \mathrm{aA}$ & $41,48 \mathrm{a}$ \\
$(3 \times 4)+7 \mathrm{~m}$ & $73,84 \mathrm{aA}$ & $71,40 \mathrm{bA}$ & $72,62 \mathrm{a}$ & $43,14 \mathrm{aA}$ & $39,48 \mathrm{aB}$ & $41,31 \mathrm{a}$ \\
$(3 \times 4)+10 \mathrm{~m}$ & $72,08 \mathrm{aA}$ & $74,39 \mathrm{abA}$ & $73,24 \mathrm{a}$ & $39,21 \mathrm{aA}$ & $40,78 \mathrm{aA}$ & $39,99 \mathrm{a}$ \\
$(3 \times 4)+7+10 \mathrm{~m}$ & $74,48 \mathrm{aA}$ & $73,13 \mathrm{abA}$ & $73,80 \mathrm{a}$ & $42,36 \mathrm{aA}$ & $41,32 \mathrm{aA}$ & $41,84 \mathrm{a}$ \\
$(3 \times 3)+15 \mathrm{~m}$ & $74,11 \mathrm{aA}$ & $70,68 \mathrm{bB}$ & $72,39 \mathrm{a}$ & $43,90 \mathrm{aA}$ & $38,73 \mathrm{aB}$ & $41,31 \mathrm{a}$ \\
$10 \times 3 \mathrm{~m}$ & $71,75 \mathrm{aA}$ & $74,35 \mathrm{abA}$ & $73,05 \mathrm{a}$ & $40,99 \mathrm{aA}$ & $40,55 \mathrm{aA}$ & $40,77 \mathrm{a}$ \\
$10 \times 4 \mathrm{~m}$ & $72,22 \mathrm{aA}$ & $73,07 \mathrm{abA}$ & $72,65 \mathrm{a}$ & $42,82 \mathrm{aA}$ & $42,64 \mathrm{aA}$ & $42,73 \mathrm{a}$ \\
\hline Média geral & $73,35 \mathrm{~A}$ & $73,43 \mathrm{~A}$ & & $41,94 \mathrm{~A}$ & $40,75 \mathrm{~B}$ & \\
\hline
\end{tabular}

Para cada variável, médias seguidas pela mesma letra minúscula nas colunas, não diferem entre si pelo teste Tukey $(\mathrm{P}<0.05)$. E seguidas pela mesma letra maiúscula nas linhas não diferem pelo teste $\mathrm{t}(\mathrm{P}<0,05)$.

Durante o período da avaliação foram observadas algumas plantas próximas à fase de floração, o que é indicativo de maturidade do pasto. Sabe-se que o avanço do estádio de maturação da forrageira implica em maior lignificação da biomassa, de maneira que a produção dos componentes potencialmente digestíveis, como os carboidratos solúveis, proteínas e minerais, tende a decrescer, e a fibra, a aumentar (GOMES, 2003; LEITE \&
EUCLIDES, 1994). Além disso, Castro et al. (1998) verificaram diminuição de $10 \%$ na digestibilidade de Brachiaria, em função do aumento nos teores de lignina em caule e folhas, o qual está relacionado ao teor de fibras na forragem $(\mathrm{FDN} \cong 72,5 \%$ a $82,5 \%$ e $\mathrm{FDA} \cong 33,5 \%$ a $45 \%$, para folhas e colmos, respectivamente) (CASTRO, 1996).

A avaliação da composição química da forragem revelou que não houve diferença significativa entre 
arranjos ou entre linha e entrelinha para porcentagem de nitrogênio $(\mathrm{N})$, teor de proteína bruta $(\mathrm{PB})$, fósforo $(\mathrm{P})$ e cobre $(\mathrm{Cu})$. Os valores médios para estas variáveis são apresentados na Tabela 4. A interação foi significativa para as porcentagens de $\mathrm{Mg}$ e Fe na forragem. Diferenças significativas entre a braquiária na linha e entrelinha de plantio do eucalipto foram encontradas quanto ao teor de potássio $(\mathrm{K})$, cálcio $(\mathrm{Ca})$, manganês $(\mathrm{Mn})$ e zinco $(\mathrm{Zn})$. Verificou-se efeito significativo dos arranjos para teores de enxofre (S), boro (B) e zinco (Zn).

Quanto ao teor de N, resultado semelhante foi constatado por Mochiutti \& Meirelles (2000), que não detectaram diferença significativa no teor de proteína bruta na pastagem de Brachiaria brizantha sob plantio de eucalipto. Em estudos de Carvalho et al. (2002), a concentração de N na parte aérea de Brachiaria decumbens também não foi afetada significativamente pela densidade arbórea, exceto em uma avaliação na época das águas, sendo o efeito atribuído mais ao período do que ao número de árvores por hectare. No entanto, Silva (1999) observou aumento do teor de N e porcentagem de $\mathrm{PB}$ na forragem sob espaçamentos maiores.

Vários autores também registraram aumento no teor de $\mathrm{N}$ e, conseqüentemente, de PB na forragem sombreada (CARVALHO et al., 1997; CASTRO, 1996; CASTRO et al., 1998; CRUZ, 1997; RIBASKI \& RAKOCEVIC, 2002; SILVA \& MAZUCHOWSKI, 1999; WILSON, 1996).

A PB existente na forragem da braquiária sob os diferentes arranjos foi superior aos valores médios ao redor de 3,0\%, encontrados por Gomes (2003). Contudo foi considerada baixa ou próxima ao limite estabelecido por Minford \& Minson (1966), citados por Gomes (2003). Estes autores citaram que o teor de PB é um dos principais fatores que limitam o desempenho dos animais em pastagens tropicais. O nível crítico na dieta, abaixo do qual o consumo é reduzido por deficiência de $\mathrm{N}$, foi estimado em 7,0\%. A média geral observada na braquiária, sob diferentes arranjos do sistema agrossilvipastoril estudado, está abaixo deste valor (Tabela 4).

Deve-se ressaltar que a biomassa avaliada incluiu material verde e em senescência ou morto. Considerando que os animais são seletivos e consomem somente componentes da pastagem de maior valor nutritivo, é provável que o teor de proteína na braquiária sob os arranjos do sistema não seja limitante ou seja em menor intensidade que o apresentado.

A concentração de $\mathrm{P}$ semelhante entre os tratamentos, está de acordo com os resultados de Costa \& Townsend (2002), avaliando a resposta de gramíneas forrageiras ao sombreamento por eucalipto. Os teores de $\mathrm{Mg}$ e $\mathrm{Fe}$ foram influenciados pelo arranjo e localização no sub-bosque do sistema agrossilvipastoril (Tabela 5). Quanto ao $\mathrm{Mg}$, não houve diferença entre os arranjos na linha. Na entrelinha de plantio, os maiores teores de $\mathrm{Mg}$ na braquiária foram encontrados nos arranjos $(3 \times 4)+7 \mathrm{~m},(3 \times 4)+7+10 \mathrm{~m}$ e ( $3 \times 3)+15 \mathrm{~m}$. Teores semelhantes de $\mathrm{Mg}$ foram registrados por Costa et al. (1998) e Costa \& Townsend (2002). A sombra na entrelinha, conforme constatado na Figuras 3, pode ter proporcionado maior teor de $\mathrm{Mg}$ na forragem, corroborando Castro et al. (2001), que constataram maior concentração de $\mathrm{Mg}$ nas folhas de Brachiaria brizantha, em função da presença deste elemento na molécula de clorofila, aumentada nas folhas sob luminosidade reduzida.

Independente do arranjo, os maiores teores de K, $\mathrm{Ca}$ e Mn foram encontrados na braquiária cultivada sob a linha de plantio. O teor de $\mathrm{Zn}$ foi exceção, sendo maior na entrelinha (Tabela 6). Carvalho et al. (1997), Cruz (1997) e Silva \& Mazuchowski (1999) citaram que a concentração de K é mais alta nas folhas de gramíneas que crescem sob a copa das árvores. Carvalho et al. (2002) constataram que a arborização de uma pastagem de Brachiaria decumbens, contribuiu para aumentar a concentração de $\mathrm{K}$ e $\mathrm{Mg}$ na forragem, na época das águas.

TABELA 4 - Teores de nitrogênio (N), proteína bruta (PB), fósforo (P) e cobre (Cu) na biomassa de Brachiaria brizantha em diferentes arranjos estruturais do sistema agrossilvipastoril com eucalipto, em Paracatu, MG.

\begin{tabular}{|c|c|c|c|c|}
\hline Arranjos & $\begin{array}{c}\mathrm{N} \\
---\mathrm{g} / \mathrm{kg}-- \\
\end{array}$ & $\begin{array}{c}\text { Proteína Bruta } \\
---\% \text {--- }\end{array}$ & 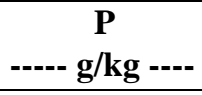 & $\begin{array}{c}\mathrm{Cu} \\
---\mathrm{mg} / \mathrm{kg} \text {--- }\end{array}$ \\
\hline$(3 \times 3)+10 \mathrm{~m}$ & 8,88 & 5,55 & 1,28 & 51,87 \\
\hline$(3 \times 4)+7 m$ & 9,71 & 6,07 & 1,38 & 42,75 \\
\hline$(3 \times 4)+10 m$ & 9,86 & 6,16 & 1,54 & 37,62 \\
\hline$(3 \times 4)+7+10 \mathrm{~m}$ & 11,12 & 6,95 & 1,42 & 49,75 \\
\hline$(3 \times 3)+15 \mathrm{~m}$ & 11,62 & 7,26 & 1,28 & 53,50 \\
\hline $10 \times 3 \mathrm{~m}$ & 9,05 & 5,65 & 1,52 & 48,75 \\
\hline $10 \times 4 \mathrm{~m}$ & 8,77 & 5,48 & 1,52 & 52,41 \\
\hline Média geral & 9,86 & 6,16 & 1,42 & 48,10 \\
\hline
\end{tabular}

Ciênc. agrotec., Lavras, v. 31, n. 3, p. 748-757, maio/jun., 2007 
TABELA 5 - Teores de magnésio (Mg) e ferro (Fe) da biomassa de Brachiaria brizantha, na linha e na entrelinha de plantio de diferentes arranjos estruturais do sistema agrossilvipastoril com eucalipto, em Paracatu, MG.

\begin{tabular}{|c|c|c|c|c|c|c|}
\hline \multirow[t]{2}{*}{ Arranjos } & \multicolumn{3}{|c|}{$\operatorname{Mg}(\mathrm{g} / \mathrm{kg})$} & \multicolumn{3}{|c|}{ Fe (mg/kg) } \\
\hline & Linha & Entrelinha & Média & Linha & Entrelinha & Média \\
\hline$(3 \times 3)+10 \mathrm{~m}$ & $2,47 \mathrm{aA}$ & $2,82 \mathrm{abA}$ & $2,65 \mathrm{a}$ & $52,55 \mathrm{aA}$ & 59,52 abcA & $56,03 \mathrm{ab}$ \\
\hline$(3 \times 4)+7 m$ & $2,62 \mathrm{aB}$ & 3,27 a $A$ & $2,95 \mathrm{a}$ & $54,72 \mathrm{bA}$ & 93,37 a $A$ & $74,05 \mathrm{a}$ \\
\hline$(3 \mathrm{x} 4)+10 \mathrm{~m}$ & $2,60 \mathrm{aA}$ & $2,30 \quad \mathrm{bA}$ & $2,45 \mathrm{a}$ & $45,17 \mathrm{aA}$ & 44,75 bcA & $44,96 \mathrm{bc}$ \\
\hline$(3 \mathrm{x} 4)+7+10 \mathrm{~m}$ & $2,72 \mathrm{aB}$ & 3,52 a $A$ & $3,12 \mathrm{a}$ & $48,80 \mathrm{aA}$ & $68,86 \mathrm{ab} A$ & $58,83 \mathrm{ab}$ \\
\hline$(3 \times 3)+15 \mathrm{~m}$ & $2,25 \mathrm{aB}$ & 3,17 a $\mathrm{A}$ & $2,71 \mathrm{a}$ & $55,82 \mathrm{aA}$ & $31,70 \quad \mathrm{cA}$ & 43,76 bc \\
\hline $10 \times 3 \mathrm{~m}$ & $2,90 \mathrm{aA}$ & $2,95 \mathrm{abA}$ & $2,92 \mathrm{a}$ & $35,00 \mathrm{aA}$ & 33,37 bcA & 34,18 bc \\
\hline $10 \times 4 \mathrm{~m}$ & $2,87 \mathrm{aA}$ & $3,02 \mathrm{abA}$ & $2,95 \mathrm{a}$ & $22,30 \mathrm{aA}$ & 32,52 bcA & 27,41 \\
\hline Média geral & $2,63 \quad \mathrm{~B}$ & $3,01 \quad \mathrm{~A}$ & & $44,91 \quad \mathrm{~A}$ & 52,01 & \\
\hline
\end{tabular}

Para cada variável, médias seguidas pela mesma letra minúscula nas colunas, não diferem entre si pelo teste Tukey $(\mathrm{P}<0.05)$. E seguidas pela mesma letra maiúscula nas linhas não diferem pelo teste $\mathrm{t}(\mathrm{P}<0,05)$.

TABELA 6 - Teores de potássio (K), cálcio (Ca), manganês (Mn) e zinco (Zn) na biomassa de Brachiaria brizantha, na linha e na entrelinha de plantio de diferentes arranjos estruturais do sistema agrossilvipastoril com eucalipto, em Paracatu, MG.

\begin{tabular}{lcccc}
\hline & $\mathbf{K}(\mathbf{g} / \mathbf{k g})$ & $\mathbf{C a}(\mathbf{g} / \mathbf{k g})$ & $\mathbf{M n}(\mathbf{m g} / \mathbf{k g})$ & $\mathbf{Z n ~ ( m g / k g )}$ \\
\hline Linha de plantio & $14,96 \mathrm{~A}$ & $1,80 \mathrm{~A}$ & $106,81 \mathrm{~A}$ & $24,68 \mathrm{~B}$ \\
Entrelinha de plantio & $13,47 \mathrm{~B}$ & $1,62 \mathrm{~B}$ & $93,57 \mathrm{~B}$ & $27,68 \mathrm{~A}$ \\
\hline
\end{tabular}

Médias seguidas pela mesma letra, nas colunas, não diferem entre si, pelo teste $\mathrm{t}(\mathrm{P}<0,05)$.

\section{CONCLUSÕES}

A forragem disponível de Brachiaria brizantha foi sempre maior na entrelinha do que na linha de plantio, independente do arranjo de plantio do eucalipto.

Os variados arranjos do sistema agrossilvipastoril praticamente não provocaram variação no teor de fibras, $\mathrm{N}$ e $\mathrm{P}$ na forragem.

Os teores de $\mathrm{Ca}$, $\mathrm{K}$ e Mn na forragem foram maiores sob as linhas de plantio. E os teores de $\mathrm{Mg}$ e $\mathrm{Zn}$ foram maiores nas entrelinhas do eucalipto.

\section{REFERÊNCIAS BIBLIOGRÁFICAS}

ANDRADE, C. M. S. de; GARCIA, R.; COUTO, L.; PEREIRA, O. G.; SOUZA, A. L. de. Desempenho de seis gramíneas solteiras ou consorciadas com o Stylosanthes guianensis cv. Mineirão e eucalipto em sistema silvipastoril. Revista Brasileira de Zootecnia, Viçosa, v. 32, n. 6, p. 18451850, nov./dez. 2003. Suplemento 2.
AROEIRA, L. J. M.; PACIULLO, D. S. C.; MACEDO, R.; ALVIM, M. J.; CARVALHO, M. M. Sistema silvipastoril para recria de novilhas leiteiras: aspectos morfológicos, produtivos e qualitativos. In: CONGRESSO BRASILEIRO DE SISTEMAS AGROFLORESTAIS - SAFs: DESENVOLVIMENTO COM PROTEÇÃOAMBIENTAL, 5., 2004, Curitiba. Anais... Colombo: Embrapa Florestas, 2004. p. 131-133. (Documentos, 98).

CARVALHO, M. M.; ALVIM, M. J.; XAVIER, D. F.; FREITAS, V. de P.; VERNEQUE, R. da S. Sustentabilidade de uma pastagem arborizada de Brachiaria decumbens em solo de baixa fertilidade natural. In: CONGRESSO BRASILEIRO DE SISTEMAS AGROFLORESTAIS: SISTEMAS AGROFLORESTAIS, TENDÊNCIA DA AGRICULTURA ECOLÓGICA NOS TRÓPICOS: SUSTENTO DA VIDA E SUSTENTO DE VIDA, 4., 2002, Ilhéus. Anais... Ilhéus: CEPLAC, 2002. CD-ROM. 
CARVALHO, M. M.; SILVA, J. L. O. da; CAMPOS JÚNIOR, B. de A. Produção de matéria seca e composição mineral de forragem de seis gramíneas tropicais estabelecidas em um sub-bosque de angico-vermelho. Revista Brasileira de Zootecnia, Viçosa, v. 26, n. 2, p. 213-218, mar./abr. 1997.

CASTRO, C. R. T. de. Tolerância de gramíneas forrageiras tropicais ao sombreamento. 1996. $247 \mathrm{f}$. Tese (Doutorado em Zootecnia) - Universidade Federal de Viçosa, Viçosa, 1996.

CASTRO, C. R. T. de; CARVALHO, M. M.; GARCIA, R.; COUTO, L. Efeito do sombreamento artificial sobre o valor nutritivo de seis gramíneas forrageiras. In: CONGRESSO BRASILEIRO EM SISTEMAS AGROFLORESTAIS: NO CONTEXTO DA QUALIDADE AMBIENTAL E COMPETITIVIDADE, 2., 1998, Belém, PA. Resumos Expandidos... Belém: Embrapa-CPATU, 1998. p. 23-25.

CASTRO, C. R. T. de; GARCIA, R.; CARVALHO, M. M.; FREITAS, V. de P. Efeitos do sombreamento na composição mineral de gramíneas forrageiras tropicais. Revista Brasileira de Zootecnia, Viçosa, v. 30, n. 6, p. 1959-1968, nov./dez. 2001.

COSTA, N. de L.; TOWNSEND, C. R. Desempenho agronômico de gramíneas forrageiras tropicais sob sombreamento de eucaliptos na Amazônia Ocidental. In: CONGRESSO BRASILEIRO DE SISTEMAS AGROFLORESTAIS: SISTEMAS AGROFLORESTAIS, TENDÊNCIA DA AGRICULTURA ECOLÓGICA NOS TRÓPICOS: SUSTENTO DA VIDA E SUSTENTO DE VIDA, 4., 2002, Ilhéus. Anais... Ilhéus: CEPLAC, 2002. CD-ROM.

COSTA, N. de L.; TOWNSEND, C. R.; MAGALHÃES, J. A.; PEREIRA, R. G. de A. Avaliação agronômica de gramíneas forrageiras sob sombreamento de seringal adulto. In: CONGRESSO BRASILEIRO EM SISTEMAS AGROFLORESTAIS: NO CONTEXTO DA QUALIDADE AMBIENTAL E COMPETITIVIDADE, 2., 1998, Belém, PA.Resumos Expandidos... Belém: Embrapa-CPATU, 1998. p. 201-203.

CRUZ, P. Effect of shade on the growth and mineral nutrition of $\mathrm{a} \mathrm{C}_{4}$ perennial grass under field conditions. Plant and Soil, Dordrecht, v. 188, n. 2, p. 227-237, Jan. 1997.

GOMES, V. M. Disponibilidade e valor nutritivo de braquiária vedada para uso na região semi-árida de Minas Gerais. 2003. 99 p. Dissertação (Mestrado em Zootecnia) - Universidade Federal de Lavras, Lavras, 2003.
LEITE, G. G.; EUCLIDES, V. P. Utilização de pastagens de Brachiaria spp. In: SIMPÓSIO SOBRE MANEJO DE PASTAGEM, 11., 1994, Piracicaba. Anais... Piracicaba: FEALQ, 1994. p. 267-297.

LI-COR. LI-COR terrestrial radiation sensors, type AS: instruction manual. Lincoln: [s.n.], 1991. 28 p.

MACEDO, R. L. G.; OLIVEIRA, A. D. de. Sistemas agroflorestais: considerações técnicas e econômicas. Lavras: DCF/UFLA, 1996. Projeto de Consultoria.

MOCHIUTTI, S.; MEIRELLES, P. R. de L. Estabelecimento de clones de eucalipto em pastagens na região de cerrados do Amapá. In: CONGRESSO BRASILEIRO DE SISTEMAS AGROFLORESTAIS: MANEJANDOA BIODIVERSIDADE E COMPONDO A PAISAGEM RURAL, 3., 2000, Manaus. Anais... Manaus: Embrapa Amazônia Ocidental, 2000. p. 171-173. (Documentos, 7).

PILLAR, V. D. P.; BOLDRINI, I. I.; LANGE, O. Padrões de distribuição espacial de comunidades campestres sob plantio de eucalipto. Pesquisa Agropecuária Brasileira, Brasília, v. 37, n. 6, p. 753-761, jun. 2002.

RIBASKI, J.; RAKOCEVIC, M. Disponibilidade e qualidade da forragem de braquiária (Brachiaria brizantha) em um sistema silvipastoril com eucalipto (Eucalyptus citriodora) no noroeste do Estado do Paraná. In: CONGRESSO BRASILEIRO DE SISTEMAS AGROFLORESTAIS: SISTEMAS AGROFLORESTAIS, TENDÊNCIA DA AGRICULTURA ECOLÓGICA NOS TRÓPICOS: SUSTENTO DA VIDA E SUSTENTO DE VIDA, 4., 2002, Ilhéus. Anais... Ilhéus: CEPLAC, 2002. CD-ROM.

SILVA, J. de C. Caracterização da madeira de Eucalyptus grandis Hill Ex. Maiden, de diferentes idades, visando a sua utilização na indústria movelveira. Revista Floresta, Curitiba, v. 32, n. 2, p. 322-323, jul./dez. 2002.

SILVA, J. M. S. da. Estudo silvicultural e econômico do consórcio de Eucalyptus grandis com gramíneas sob diferentes espaçamentos em áreas acidentadas. 1999. 115 p. Dissertação (Mestrado em Ciência Florestal) Universidade Federal de Lavras, Lavras, 1999.

SOCIEDADE BRASILEIRA DE SILVICULTURA.

Estatísticas. Disponível em: <http:/www.sbs.org.br/ estatisticas.htm>. Acesso em: 21 jan. 2005. 
SILVA, V. P. da; MAZUCHOWSKI, J. Z. Sistemas silvipastoris: paradigma dos pecuaristas para a agregação de renda e qualidade. Curitiba: UFPR, 1999. 52 p. (Série informação técnica, 50).

SILVA, V. P. da; VIEIRA, A. R. R.; CARAMORI, P. H.; BAGGIO, A. J. A radiação fotossinteticamente ativa e a produção de pastagem em sistema silvipastoril. In: CONGRESSO BRASILEIRO DE AGROMETEOROLOGIA, 11., 1999, Florianópolis. Anais... Florianópolis: Sociedade Brasileira de Agrometeorologia, 1999. CD-ROM.
SOARES FILHO, C. V. Avaliação de dez gramíneas forrageiras na região noroeste do Estado de São Paulo. 2001. 117 f. Tese (Doutorado em Zootecnia) - Universidade Estadual Paulista, Jaboticabal, 2001.

WILSON, J. R. Shade-stimulated growth and nitrogen uptake by pasture grasses in a subtropical environment. Australian Journal of Agricultural Research, Collington, v. 47, p. 1075-1093, 1996. 